\title{
France to strengthen regional centres ...
}

[PARIS] The French government has announced plans for a multi-billion-dollar regional development project for higher research and education, known as the 'University of the Third Millennium' (U3M). One of its goals will be the creation of a national network of centres of research excellence with regional universities as the nodes.

The project, to run from 2000 to 2006 , is part of a vast multi-annual programme organized by an interministerial committee known as CIADT, which is responsible for planning public infrastructure projects. CIADT's costs are met equally by the state and regional government. Such programmes have traditionally been given a high political priority in France, and are generally adhered to, irrespective of changes of government.

$\mathrm{U} 3 \mathrm{M}$ will be organized along the same lines as its predecessor, University 2000 (U2000), a FF42 billion ( $\$ 7.4$ billion) programme launched by Lionel Jospin, the present prime minister, during his spell as education minister from 1988 to 1992 . U2000 has resulted in the construction of about 1.5 million square metres of university space.

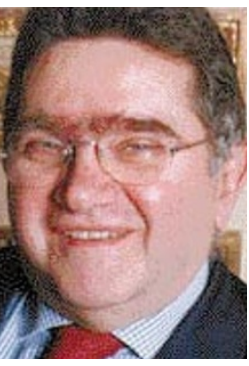

Claude Allègre, the minister for national education and research, said last week that the costs of $\mathrm{U} 3 \mathrm{M}$ would be at least as significant as those of U2000, but that its goals would be very different. The main emphasis would Allègre: has scope to be on research infrareallocate resources. structure, such as high-speed computer networks and new biotechnology centres.

Indeed, research was almost absent from U2000, which was targeted towards refurbishing France's universities, after decades of neglect, and creating space to absorb a massive rise in student numbers. Priority was also given to regional development to offset the historic centralization of higher education in the Paris region.

But demographic changes mean that student numbers are set to plummet, freeing up resources for other goals. These will be drafted by a new national 'strategic committee'

\section{Biology federation urged to widen focus}

[WASHINGTON] The US Federation of American Societies for Experimental Biology (FASEB) is being pressed by some of its $\mathbf{1 7}$ affiliated societies to work harder to represent the views of individual investigators on professional issues, as well as lobbying for research funds.

At a ten-yearly retreat to assess the strategy of the federation, held two weeks ago at Potomac, Maryland, representatives of the societies said they would like FASEB to pursue issues such as graduate training and the quality of peer review with the same energy with which it argues for more funding for biomedical research.

At a similar retreat in 1989, FASEB was effectively reconstituted as the public affairs arm of its member societies. It has since expanded from six societies with 26,000 members to 17 societies with 56,000 members, and has emerged as the main public voice of US biomedical researchers.

David Kaufman, professor of pathology and laboratory medicine at the University of North Carolina and the new vice-president of FASEB, will take over as its president next July. He says he would like FASEB to develop policies on such issues as the burden of regulation on scientists, restrictions that affect their use of patented research tools and data, scientific integrity, and career development for young scientists.

"It is important to me that we be seen not only to be raising funds for research, but also in an advocacy role for the individual scientist," Kaufman says. He acknowledges that FASEB had "done a great deal" already in these areas, but often on a reactive basis. "My goal is not just to do it reactively, but to think about these things and develop policies on them at an early stage, perhaps bringing issues to the fore."

FASEB staff point out that it is already active in policy areas. Last year, for example, it produced a consensus report on the need for reform of graduate education for life scientists. But according to one official who attended the Potomac retreat, several society representatives said that FASEB should place more emphasis on professional issues. "They wanted us to focus more broadly although, to tell you the truth, I thought we were doing that already," says the official.

FASEB has scored successes in recent years by calling for increases in funding at the National Institutes of Health that were then implemented by appropriators in Congress. The societies may now feel that this success can be extended to other areas of professional interest to their members. But Michael Jackson, executive director of FASEB, says it has already sought to address such issues. The reason some people may have the impression that FASEB is fixated with money for research, he says, is that the funding process recurs annually. "With other issues, once they are addressed, they stay addressed," he says. Colin Macilwain chaired by Guy Aubert, a former director general of Centre National de la Recherche Scientifique (CNRS). Committee members include several university vice-chancellors and scientists such as Jean-Marie Lehn, winner of the 1987 Nobel prize for chemistry.

Proposals will be drawn up in parallel by regional groups of university and local-government officials. A detailed proposal for $\mathrm{U} 3 \mathrm{M}$ is expected to be completed by June next year.

"We are no longer in a phase of expansion of student numbers, during which the quantitative needs were prevalent," says Edouard Brezin, chairman of the board of directors of the CNRS and a member of the new committee. "The emphasis on research facilities and quality will be much more important now."

In particular, Allègre sees the promise of a large investment in research infrastructure as a means of building on excellent existing regional research universities - for example, at Strasbourg, Compiègne and Grenoble - to create large, research-based technology universities based on US models such as the Massachusetts Institute of Technology.

The government recently allocated FF1 billion to create a national technology network to bring together public and private laboratories in key sectors (see Nature 393, 203; 1998), and industrial development will be a "priority" within U3M, says Aubert. Under preliminary proposals, a national network of biotechnology science parks would be created, for example, centred on the new Génopôle centre at Evry near Paris (see Nature 392, 214; 1998).

More broadly, the programme seems to be a reinforcement of the policy of creating regional research 'pôles', which are federations of laboratories that bring together scientists from local universities, research centres, hospitals and industry to create a critical mass in a research project at a single site.

These would be backed up by the construction of shared national science facilities. Allègre has asked research organizations to submit a 'wish list' of medium-sized equipment. Among those he has earmarked as priorities are the creation of a supercomputing network, the building of new structural analysis centres, and an upgrade of the national research Internet network, Renater.

Allègre will benefit from the fact that more than half of France's research and teaching staff are due to retire over the next decade, providing extra scope for reallocating priorities and resources.

"The idea of defining locations for national institutes in various disciplines, which would receive the means needed for modern research, rather than spreading resources thinly, certainly goes in a welcome direction," says Brezin.
DeclanButler 